\title{
Postnatal care service utilization and associated factors among women in Goba woreda, Bale zone, Ethiopia: A community based cross-sectional study
}

\author{
Debebe Wordofa1), Asfaw Hailu), Yonas Lamore3), Abate Lette1) \\ ${ }^{1)}$ Department of Public Health, Faculty of Health Science, Goba Referral Hospital, \\ Madda Walabu University, Bale Goba, Ethiopia \\ ${ }^{2)}$ Goba Woreda Health Office, Bale Goba, Ethiopia \\ 3)Department of Environmental Health, Faculty of Health Science, \\ Debre Markos University, Debre Markos, Ethiopia
}

\begin{abstract}
Background: Postnatal care of mothers is essential to reduce maternal morbidity and mortality. Providing postnatal care to recently delivered mothers is quite essential. The aim of the study was to determine the postnatal care utilization and associated factors among women who gave birth in the last 12 months in Goba woreda, Bale Zone, Ethiopia, 2020.

Subjects and Method: A community based quantitative cross-sectional study was conducted in Goba woreda from March to April, 2020 among reproductive age group mothers who gave birth the in last 12 months prior this data collection. In this study 422 subjects were conducted using Lottery method to select them. The independent variables were socio-demographics charctestics and obstetrics' health related factors with outcome variable of post-

mothers $(\mathrm{OR}=1.96 ; 95 \% \mathrm{CI}=1.06$ to $3.62 ; \mathrm{p}=$ 0.050) maternal knowledge on postpartum danger sign \& symptoms $(\mathrm{OR}=1.78 ; 95 \% \mathrm{CI}=$ 1.16 to $2.72 ; \mathrm{p}=0.010)$ pregnancy desire $(\mathrm{OR}=$ 1.89; $95 \% \mathrm{CI}=1.67$ to $3.35 ; \mathrm{p}=0.050)$ ANC visit $(\mathrm{OR}=2.80 ; 95 \% \mathrm{CI}=1.32$ to $5.97 ; \mathrm{p}=0.010)$ and place of deliver $(\mathrm{OR}=2.09 ; 95 \% \mathrm{CI}=1.30$ to $3.34 ; \mathrm{p}=0.010$ ) had showed statistical significant association with postnatal care utilization.

Conclusion: More than half of respondents in Goba woreda were not utilized postnatal care service. Maternal educational status, maternal knowledge on postnatal danger signs and symptom, pregnancy desire for youngest child, ANC attendance and place of delivery found to be independent predictors for PNC service utilization.
\end{abstract} natal care service utilization. Binary and multivariable logistic regressions analysis were computed to evaluate the factors associated with postnatal care services utilization.

Results: In this study a total of 422 women were interviewed with a response rate of $100 \%$. Out of the total respondents, 178 (42.2\%) utilized postnatal care service after delivery within six weeks of their last birth. Educational level of
Keywords: postnatal care, delivery, postpartum, Bale zone, danger sign

\section{Correspondence:}

Yonas Lamore. Department of Environmental Health, Faculty of Health Science, Debre Markos University. Debre Markos, Ethiopia. Email: yonas384@gmail.com.

Cite this as:

Wordofa D, Hailu A, Lamore Y, Lette A (2021). Postnatal care service utilization and associated factors among women in Goba woreda, Bale zone, Ethiopia: A community based cross-sectional study. J Matern Child Health. 06(04): 455-466. https://doi.org/10.26911/thejmch.2021.06.04.07.

\section{(c) (7) Journal of Maternal and Child Health is licensed under a Creative Commons}

Attribution-NonCommercial-ShareAlike 4.o International License.

\section{BACKGROUND}

Postnatal period is the time from delivery of baby till the first 42 days. Risks of maternal and new born deaths are greatest during the first 24 to 48 hours after birth. Therefore,
Providing Postnatal Care (PNC) to recently delivered mothers is quite essential during this period (Matthews et al., 2008). Globally every year, 40 million women give birth at home without the help of a skilled birth 
Wordofa et al./ Postnatal care service utilization and associated factors among women in Ethiopia

attendant. An estimated of 800 women die during pregnancy or childbirth and around 8,000 newborn babies die during their first month of life per day. Nearly all newborn and maternal deaths $99 \%$ occur in developing countries, where pregnant women and newborn babies lack access to basic health care services before, during and after delivery (Save the children, 2013).

In Ethiopia the estimate of maternal mortality ratio for the 7-year period preceding the 2016 EDHS is 412 deaths per 100,000 live births; that is, for every 1,000 births there are about 4 maternal deaths (EDHS, 2016). Studies have shown that postnatal care services utilization is affected by several factors including maternal age, educational level of the women, occupational status of women and husbands, place of delivery, mode of delivery, number of pregnancies, awareness about obstetric related danger sign, and awareness about PNC services (Khanal et al., 2014; Workineh and Hailu, 2014; Ambel et al., 2015; Berhanu et al., 2016; Limenih et al., 2016). Only 17 percent of women received postnatal care within two days (EDHS, 2016).

A study conducted on Postnatal Care Service Utilization and Associated Factors among Mothers in Lemo Woreda, Ethiopia showed that many opportunities are missed with low PNC coverage including exclusive breastfeeding, PMTCT, providing of family planning and maternal and new born care (Belachew et al., 2016).

Despite there is no research conducted regarding postnatal care service utilization in the study area. This study was help to identifying factors that affecting postnatal care service utilization. The finding of this study was also help as an input for program managers and other stakeholder who work on maternal and child health to strengthen PNC service utilization and it also used as a base line for other researchers for further study.

\section{SUBJECTS AND METHOD}

\section{Study Design}

A community based quantitative crosssectional study was conducted in Goba woreda from March to April, 2020 among reproductive age group mothers who gave birth the in last 12 months prior this data collection. The study was conducted in five rural kebeles (the smallest government administrative structure). Goba town is found in Bale zone, Oromiya regional state, Ethiopia. It is one of the 18 woreda in Bale zone. The woreda is located $444 \mathrm{Km}$ from Addis Ababa and $13 \mathrm{Km}$ from Zonal town; Bale Robe. According to the last census survey (2007) projection to 2020, the estimated population of Goba woreda is 53,121 , of whom 26,030 males and 27,091 females.

\section{Population and Sample}

For objective one, single population proportion formula and for objective two, by using Epi-info version7.4.1 stat calc software was used to calculate the sample size for factors which have significant association in previous studies affecting postnatal care service utilization. The study was conducted out of 15 rural kebeles in five kebeles of Goba Rural woreda. Lottery method was employed to select the study participants. All women who have gave birth in the last 12 months prior to the data collection period in Goba rural kebeles were included in the study.

\section{Study Variables}

The dependent variable was postnatal care service utilization and the independent variables were socio-demographics charcteristics and obstetrics' health related factors.

\section{Operational Definition of Variables Postnatal care utilization: Women had} at least one check-up during the first 6 weeks by the health professional after home 
Wordofa et al./ Postnatal care service utilization and associated factors among women in Ethiopia

delivery and, for those mothers who gave birth at the health institution came back for postnatal care services after they were discharged to their homes.

Postnatal care: Refers to the assistance or care given to mother and baby by health workers during the postnatal follow up period such as counsel on baby care, support breastfeeding, maternal nutrition, provide contraception service, and immunize the infant.

Postpartum period: Starts after expulsion of placenta up to 42 days (6 weeks).

\section{Study Instruments}

The questionnaire was adapted by reviewing literatures of similar studies aiming on postnatal care service utilization and its associated factors (Khanal et al., 2014; Workineh and Hailu, 2014; Ambel et al., 2015; Berhanu et al., 2016; Limenih et al., 2016). The questioners have three parts, which are socio demographic characteristics, obstetric health related factor, and mother's awareness on postnatal care service utilization.

Five diploma and two BSc nurses were selected for data collector and supervisor respectively. The training was given for data collectors and supervisor for two days. The training session included the general objective of the study, content of the questionnaire, ways how to keep confidentiality and privacy and mechanisms how to resolve when a problem arises.

The questionnaire was prepared first in English then translated to Afan Oromo, which is the local language, and to check its consistency, it was back translated to English by an expert of both languages. The questioner was pretested 5\% from total sample size on women who had given birth in the past six weeks to one-year prior the data collection period on Wajitu-Shabe kebele. The data collected for pre-test did not included in the actual data of the thesis. In order to maintain quality of the data, the training was given for both data collectors and supervisors for two days by investigator in data collection procedures.

\section{Data Analysis}

First the data was checked for its completeness. Then, by entered in to Epi info 7 versions, the data was clean and corrected for errors and exported to Statistical Package for Social Science (SPSS) version 20. Descriptive statistics was used to determine the proportion of postnatal care service utilization. Binary and multiple logistic regressions were computed to assess the factors associated with postnatal care services utilization. Logistic regression analysis was carried out to see the independent effect of each variable on the outcome. Odds ratio and 95\% CI was used to measure the statistical association. $\mathrm{P}$ value 0.05 was used to determine the statistical significance of the tests. Finally, the result was presented in texts, tables and graphs.

\section{Research Ethics}

Formal letter was obtained from Madda Walabu University, Goba Referral Hospital, and School of Health Science with reference number 01/02/1594. Supportive letters were obtained from Bale Zone Health Department and Goba woreda Administrative office. Participants were informed about the objective of the study and consent was obtained from the mothers. All the information given by the respondents was used for research purposes only and confidentiality was maintained by omitting any personal identifiers of the respondents. Participation was on voluntary basis and they could withdraw from the study at any time of data collection.

\section{RESULTS}

\section{Sample Characteristics}

A total of 422 women who gave birth in the last two years prior to this survey were interviewed with a response rate of $100 \%$. 
The mean age of the respondents was 29.55 $\quad(\mathrm{SD}=6.34)$ years (See Table 1).

Table 1. Socio-demographics charactestic of respondent's in Goba Woreda, Bale Zone, Southeast Ethiopia, 2020.

\begin{tabular}{|c|c|c|}
\hline Variable & Frequency $(\mathbf{N})$ & Percentage (\%) \\
\hline \multicolumn{3}{|l|}{ Age } \\
\hline $15-24$ & 108 & 25.6 \\
\hline 25-34 & 199 & 47.2 \\
\hline$>35$ & 115 & 27.2 \\
\hline \multicolumn{3}{|l|}{ Religion } \\
\hline Muslim & 351 & 83.2 \\
\hline Orthodox & 71 & 16.8 \\
\hline \multicolumn{3}{|l|}{ Ethnicity } \\
\hline Oromo & 418 & 99.1 \\
\hline Amhara & 4 & 0.9 \\
\hline \multicolumn{3}{|l|}{ Marital status } \\
\hline Single, divorce and widowed & 19 & 4.5 \\
\hline Married & 403 & $95 \cdot 5$ \\
\hline \multicolumn{3}{|l|}{ Occupation } \\
\hline House wife (un employed) & 410 & 97.2 \\
\hline Employed & 12 & 2.8 \\
\hline \multicolumn{3}{|c|}{ Educational Status of mother $(\mathrm{N}=422)$} \\
\hline No formal education & 105 & 24.9 \\
\hline Primary education & 179 & 42.4 \\
\hline Secondary and above education & 138 & 32.7 \\
\hline \multicolumn{3}{|c|}{ Educational Status of husband $(\mathrm{N}=403)$} \\
\hline No formal education & 85 & 21.1 \\
\hline Primary education & 176 & 43.7 \\
\hline Secondary and above education & 142 & 35.2 \\
\hline \multicolumn{3}{|l|}{ Monthly income } \\
\hline$<500$ Eth Birr & 94 & 22.3 \\
\hline 501-1500 Eth Birr & 258 & 61.1 \\
\hline 1501-250oEth Birr & 53 & 12.6 \\
\hline 2500+ Eth Birr & 17 & 4.0 \\
\hline
\end{tabular}

\section{Postnatal care and obstatric health} related factors

From total resondants, majority 335 (84.1\%) of the pregnancy desire for youngest child were intended. All most all 384 (91\%) respondents had a history of ANC follow up out of these, $42(10.9 \%)$ were visited one times and 95 (24.7\%) were visited four and above times. From those ANC visited 316 (82.3\%) were Iron supplemented. From all participants, only 6 (1.4\%) faced danger sign of pregnancy during last child birth. Concerning place of last delivery, 308 (73\%) gave birth in health institution with the help of skilled provider. From those who delivered in health institution, majority 226
(73.4\%) were delivered at Health Center, 69 (22.4\%) were delivered at Hospital and 13 (4.2\%) were delivered at Health post. Out of 308 mothers who delivered at Health institution, 222(72.1\%) were given appointment for postnatal care by the health care professionals before discharge. The remaining 86 (27.9\%) participants were not informed to have postnatal care by the health professionals before discharge. Regarding child sex from single birth out of 415 respondants, 248 (59.8\%) were male and the remaining 167 (40.2\%) female. Concerning number of children, majority, 193 (45.7\%) of respondents had 3 to 4 children and only 80 (19\%) had 5 and above children. Regarding PNC 
Wordofa et al./ Postnatal care service utilization and associated factors among women in Ethiopia

service utilization decision making power, made decision together with their husbands $342(81 \%)$ of respondents stated that they

(See Table 2).

Table 2. Obstetrics' health related factors among the respondent's in Goba Woreda, Bale Zone, Southeast Ethiopia, 2020.

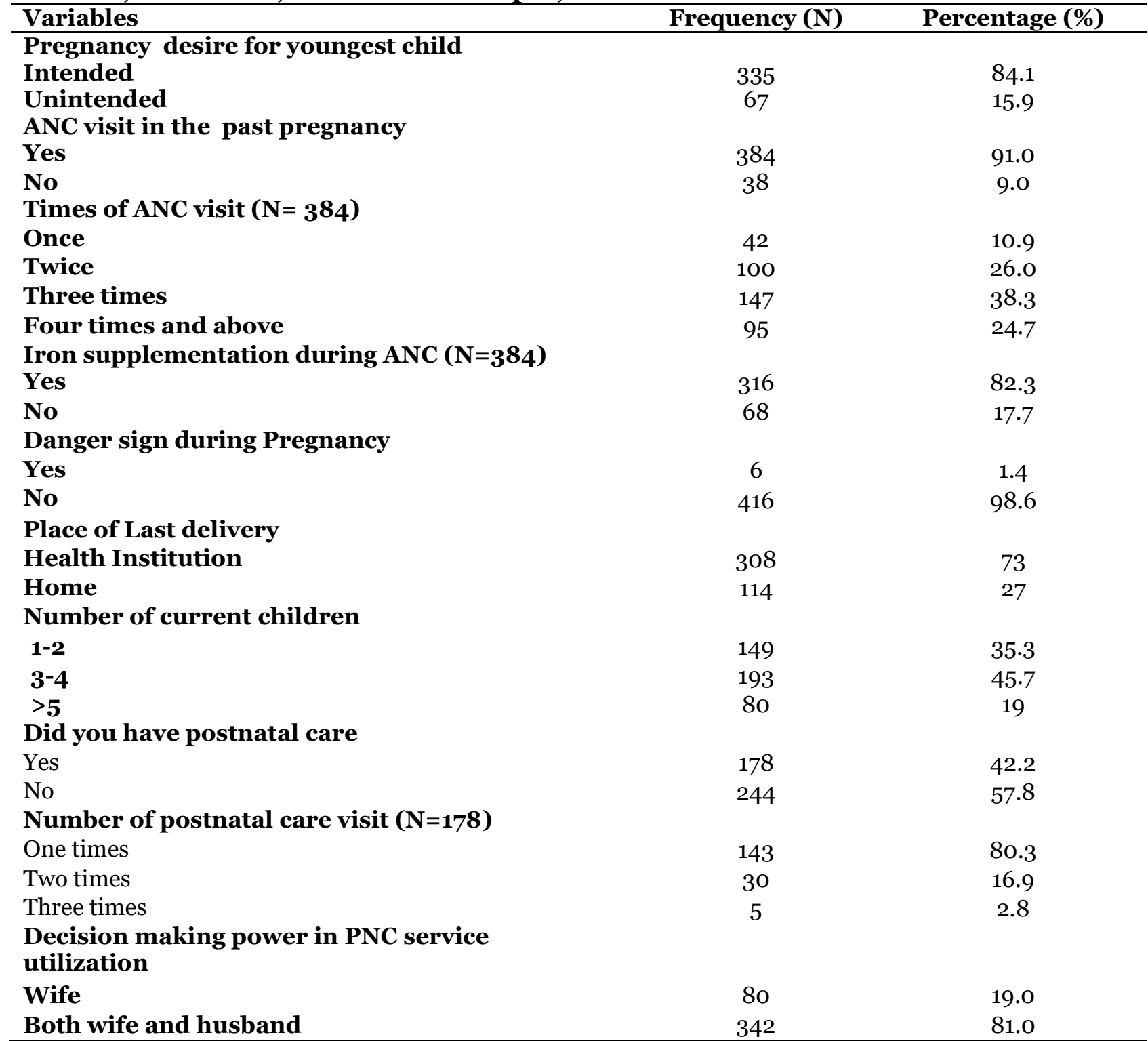

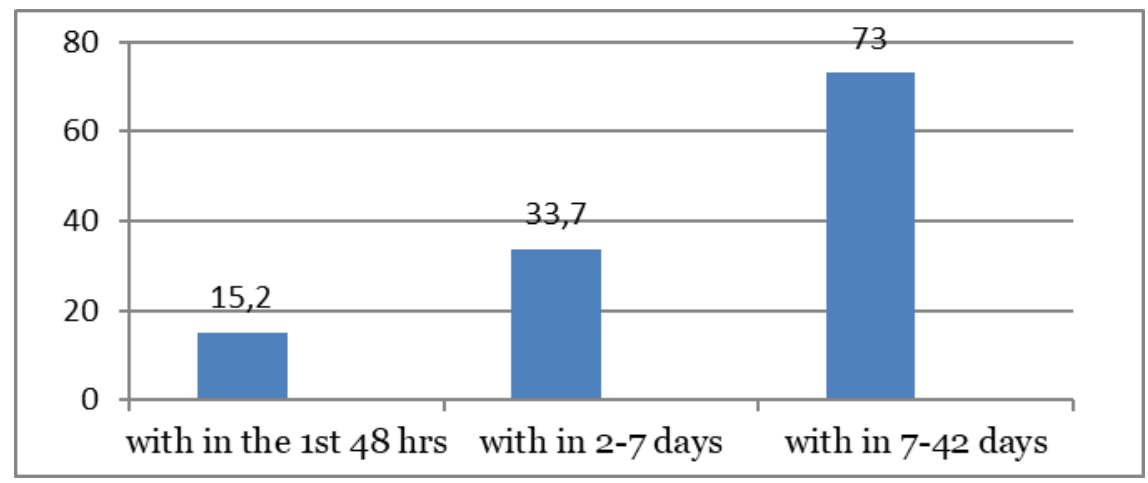

Figure 1: The percentage of respondents time of PNC check up in Goba Woreda, Bale Zone, Southeast Ethiopia, 2020. 
Wordofa et al./ Postnatal care service utilization and associated factors among women in Ethiopia

The data revealed that only 27(15\%) utilized PNC with in the first 48 hours after child birth and 130 (73\%) of respondents received postnatal care service within 7 to 42 days of child birth (See Figure 1).

\section{Predictors of postnatal care utiliza- tion}

In multivariable logistic regression model, after we entered the above 10 candidate variables the following five variables; educational status of mothers, whether or not know maternal dander sign and symptoms, pregnancy desire for youngest child, ANC visit and place of delivery had showed statistical significant association with PNC utilization. The odds of having postnatal care visit for those women who attended to Secondary and above education were nearly two times more likely to have PNC visit than those no formal education (AOR= $1.96,95 \% \mathrm{CI}=1.06$ to 3.62 ).

In addition, knowledge of respondents on maternal danger sign and symp- tom of postpartum has also another predictor of PNC service utilization. Those mothers who know at least one maternal danger sign and symptom nearly two times more likely to be utilized postnatal care service than those who did not about maternal danger sign and symptom $(\mathrm{AOR}=1.78,95 \%$ $\mathrm{CI}=1.16$ to 2.72 ). Those mothers who had planned pregnancy desire for youngest child were nearly two times more likely utilized postnatal care service than those unplanned $(\mathrm{AOR}=1.89,95 \% \mathrm{CI}=1.67$ to 3.35). ANC visit was also statically significant with postnatal care service utilization. Those mothers who had attended ANC were nearly three times more likely utilize postnatal care service than non-attended $(\mathrm{AOR}=2.80,95 \% \mathrm{CI}=1.32$ to $5 \cdot 97)$. Women who delivered at health institution were two times more likely utilized postnatal care than those mothers who gave their last birth at home $(\mathrm{AOR}=2.09,95 \% \mathrm{CI}=1.30$ to 3.34) (See Table 3).

Table 3. Bivariable analysis of factors associated with postnatal care utilization Among Women who gave birth in the last 12 Months in Goba woreda, Bale Zone, Ethiopia, 2020.

\begin{tabular}{|c|c|c|c|c|c|c|c|c|}
\hline \multirow{3}{*}{ Variable } & \multicolumn{4}{|c|}{ PNC utilization } & \multirow{3}{*}{$\mathbf{O R}$} & \multicolumn{2}{|c|}{$95 \% \mathrm{CI}$} & \multirow{3}{*}{$\mathbf{p}$} \\
\hline & \multicolumn{2}{|c|}{ Yes } & \multicolumn{2}{|c|}{ No } & & \multirow{2}{*}{$\begin{array}{l}\text { Lower } \\
\text { limit }\end{array}$} & \multirow{2}{*}{$\begin{array}{l}\text { Upper } \\
\text { limit }\end{array}$} & \\
\hline & $\mathbf{n}$ & $\%$ & $\mathbf{n}$ & $\%$ & & & & \\
\hline \multicolumn{9}{|l|}{ Age } \\
\hline $15-24$ & 43 & 39.8 & 65 & 60.2 & 1.08 & 0.64 & 1.85 & 0.770 \\
\hline $25-34$ & 87 & $43 \cdot 3$ & 112 & 56.3 & 0.92 & 0.58 & 1.47 & 0.733 \\
\hline$>35$ & 48 & 41.7 & 67 & 58.3 & 1 & & & \\
\hline \multicolumn{9}{|l|}{ Marital status } \\
\hline Married & 172 & 42.7 & 231 & $57 \cdot 3$ & 0.62 & 0.23 & 1.66 & 0.770 \\
\hline Others* & 6 & 31.6 & 13 & 68.4 & 1 & & & \\
\hline \multicolumn{9}{|l|}{ Occupation } \\
\hline House wife (un employed) & 171 & 41.6 & 240 & 58.4 & 2.46 & 0.71 & 8.52 & 0.151 \\
\hline $\begin{array}{l}\text { Employed } \\
\text { Maternal education }\end{array}$ & \multicolumn{7}{|c|}{ Maternal education } & \\
\hline No formal education & 55 & 54.4 & 50 & 47.6 & 1 & & & \\
\hline Primary education & 72 & 40.2 & 107 & 59.8 & 1.82 & 1.11 & 2.96 & 0.017 \\
\hline Secondary and above & 51 & 37 & 87 & 63 & 1.95 & 1.17 & 3.27 & 0.011 \\
\hline $\begin{array}{l}\text { Husband education } \\
(\mathrm{N}=403)\end{array}$ & & & & & & & & \\
\hline No formal education & 44 & 51.8 & 41 & 48.2 & 1 & & & \\
\hline Primary education & 67 & 38.1 & 109 & 61.9 & 1.75 & 1.04 & 2.95 & 0.037 \\
\hline $\begin{array}{l}\text { Secondary and above } \\
\text { education }\end{array}$ & 61 & 43 & 81 & 57 & 1.43 & 0.83 & 2.45 & 0.198 \\
\hline
\end{tabular}


Wordofa et al./ Postnatal care service utilization and associated factors among women in Ethiopia

\begin{tabular}{|c|c|c|c|c|c|c|c|c|}
\hline \multicolumn{9}{|l|}{ Monthly income } \\
\hline$<500$ Eth Birr & 38 & 40.4 & 56 & 59.6 & 1.31 & 0.46 & 3.70 & 0.610 \\
\hline 501-1500 Eth Birr & 108 & 41.9 & 150 & 58.1 & 1.24 & 0.46 & $3 \cdot 30$ & 0.675 \\
\hline 1501-2500Eth Birr & 25 & 47.2 & 28 & 52.8 & 1.07 & 0.36 & 3.21 & 0.898 \\
\hline$>2500$ Eth Birr & 7 & 41.2 & 10 & 58.8 & 1 & & & \\
\hline \multicolumn{9}{|l|}{$\begin{array}{l}\text { Heard of postnatal } \\
\text { care services } \\
\text { utilization }\end{array}$} \\
\hline Yes & 146 & $43 \cdot 7$ & 188 & 56.3 & 0.74 & 0.45 & 1.20 & 0.215 \\
\hline No & 32 & 36.4 & 56 & 63.6 & 1 & & & \\
\hline \multicolumn{9}{|l|}{$\begin{array}{l}\text { Know at least one } \\
\text { maternal danger sign } \\
\text { and symptoms during } \\
\text { postpartum }\end{array}$} \\
\hline Yes & 89 & 36.8 & 153 & 63.2 & 1.68 & 1.14 & 2.49 & 0.009 \\
\hline No & 89 & 49.4 & 91 & 50.6 & 1 & & & \\
\hline \multicolumn{9}{|l|}{$\begin{array}{l}\text { Know at least one } \\
\text { neonatal danger sign } \\
\text { symptoms }\end{array}$} \\
\hline Yes & 118 & 43.4 & 154 & 56.6 & 0.87 & 0.58 & 1.31 & 0.501 \\
\hline No & 60 & 40 & 90 & 60 & 1 & & & \\
\hline \multicolumn{9}{|l|}{$\begin{array}{l}\text { Pregnancy desire for } \\
\text { youngest child }\end{array}$} \\
\hline Intended & 139 & 39.2 & 216 & 60.8 & 2.16 & 1.27 & 3.68 & 0.004 \\
\hline Unintended & 39 & 58.2 & 28 & 41.8 & 1 & & & \\
\hline \multicolumn{9}{|l|}{$\begin{array}{l}\text { ANC visit in the past } \\
\text { pregnancy }\end{array}$} \\
\hline Yes & 156 & 40.6 & 228 & 59.4 & 2.01 & 1.02 & 3.95 & 0.043 \\
\hline No & 22 & $57 \cdot 9$ & 16 & 42.1 & 1 & & & \\
\hline \multicolumn{9}{|l|}{$\begin{array}{l}\text { Place of Last } \\
\text { delivery }\end{array}$} \\
\hline Health Institution & 118 & 38.3 & 190 & 61.7 & 1.79 & 1.16 & 2.76 & 0.009 \\
\hline Home & 60 & 52.6 & 54 & 47.4 & 1 & & & \\
\hline \multicolumn{9}{|l|}{$\begin{array}{l}\text { Appointed for } \\
\text { postnatal care service } \\
\text { utilization at } \\
\text { discharge }(\mathbf{3 3 2})\end{array}$} \\
\hline Yes & 86 & 38.7 & 136 & 61.3 & $\begin{array}{l}0.9 \\
4\end{array}$ & 0.56 & 1.57 & 0.804 \\
\hline \multirow{2}{*}{\multicolumn{9}{|c|}{$\begin{array}{l}\text { Number of } \\
\text { current children }\end{array}$}} \\
\hline & & & & & & & & \\
\hline $1-2$ & 58 & 38.9 & 91 & 61.1 & 1.42 & 0.82 & 2.46 & 0.211 \\
\hline $3-4$ & 82 & 42.5 & 111 & 57.5 & 1.23 & 0.73 & 2.07 & 0.448 \\
\hline $5^{+}$ & 38 & $47 \cdot 5$ & 42 & 52.5 & 1 & & & \\
\hline \multicolumn{9}{|l|}{$\begin{array}{l}\text { Decision making } \\
\text { power }\end{array}$} \\
\hline Wife . & 28 & 35 & 52 & 65 & 1.45 & 0.87 & 2.41 & 0.150 \\
\hline Both wife and husband & 150 & 43.9 & 192 & 56.1 & 1 & & & \\
\hline
\end{tabular}


Wordofa et al./ Postnatal care service utilization and associated factors among women in Ethiopia

Table 4. Multivariable analysis of factors associated with postnatal care utilization among women who gave birth in the last 12 months in Ethiopia, 2020.

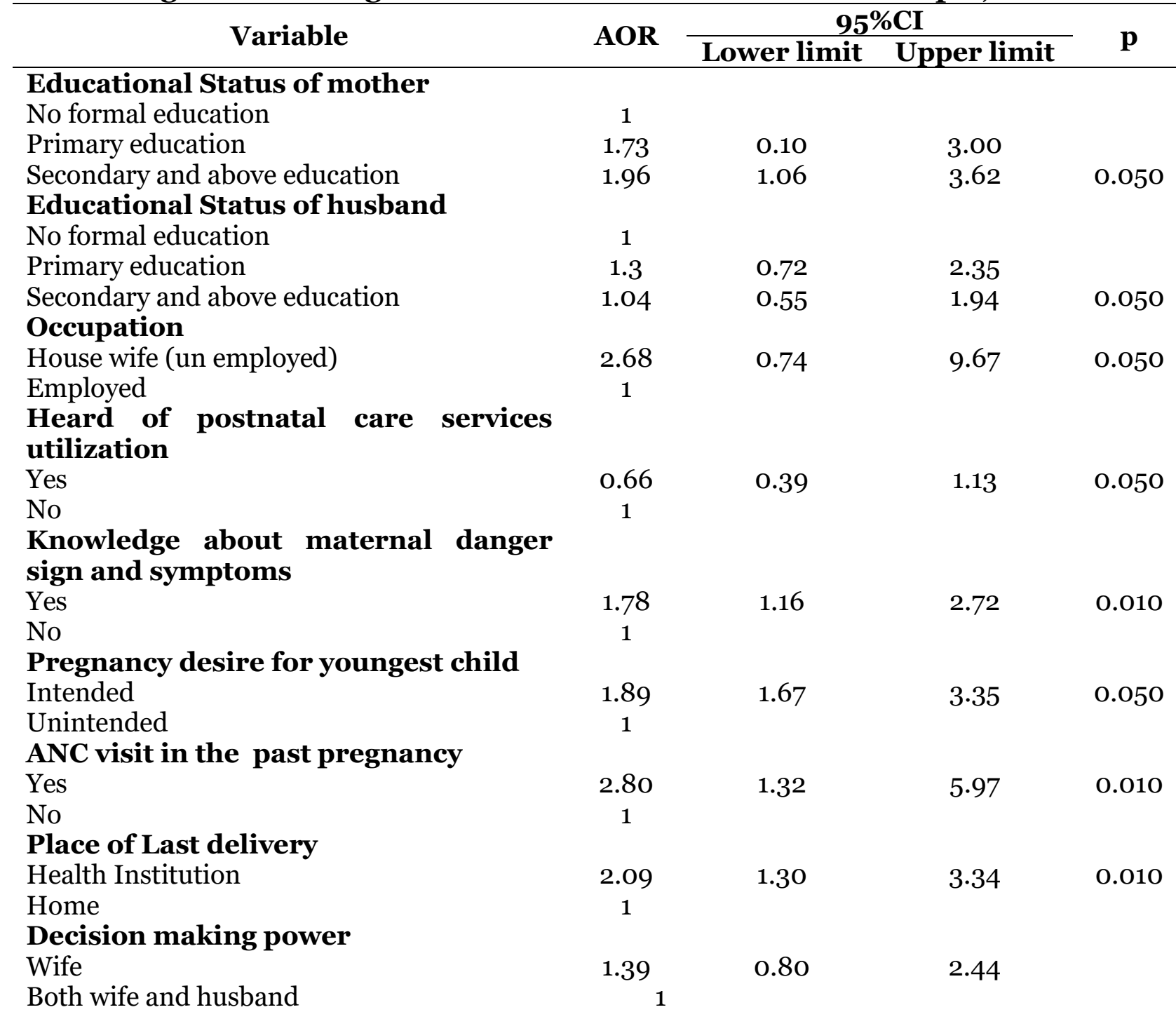

\section{DISCUSSION}

Evidence from the present study indicated that postnatal care service utilization was 42.2\%. This result is higher than with the studies done in Debre Markos town, North western Ethiopia 33.5\% (Limenih et al., 2016), Jabitena District, Amhara 20.20\% (Workineh and Hailu, 2014), Asella Town 35\% (Tafesse, 2015b), Nepal 25.1\% (Paudel et al., 2013), Nigeria 16.9\% (Usman et al., 2015). This difference could be due to the improvement in accessibility of health facilities and the time difference between these studies.

This finding was lower when comparable with the finding of study done in Lemo Woreda,Ethiopia 51.4\% (Belachew et al., 2016), Hossaian, South Ethiopia 51.4\% (Dutamo et al., 2015) and Addis Ababa 65.5\% (Berhanu et al., 2016). This discrepancy could be due to less awareness and educated of the mothers on the importance of postnatal care service utilization it might be also due to methodology difference and social context variation between the present study and previous studies. In this study, it has been identified that five variables which is significantly associated with PNC service 
utilization. These included maternal educational status, knowledge of maternal danger signs and symptom, desire of pregnancy plan for youngest child, ANC and place of delivery.

Regarding educational status, mothers who had attended secondary and above educational level were more likely utilize PNC service than those who had no formal education. This finding is almost similar with previous studies (Workineh and Hailu, 2014, Central Statistical Agency, 2011, Khanal et al., 2014, Somefun and Ibisomi, 2014, Paudel et al., 2013). This could be explained by the fact that education has a valuable input in enhancing female autonomy and helps women develop greater confidence and capability to make decisions about their own health. Thus, educated women try to find higher quality of health services and have greater ability to use health care inputs that offer better health outcomes.

Knowledge on danger signs and symptoms of the mothers has also another positive association with PNC service utilization. Mothers who had knowledge for at least one possible postnatal danger sign and symptoms were more likely to utilize PNC service as compared to those who did not mention any postpartum danger signs and symptoms. This finding is supported by local studies conducted in Lemo Woreda, Hadiya Zone (Belachew et al., 2016) and Jabitena district, Amhara region (Workineh and Hailu, 2014). The possible justification for these positive associations could be knowledge on obstetric danger signs and symptom during puerperium is an important factor in motivating mothers and their families to attend health care service at the earliest opportunity with the intention of prevention, early detection and getting managed their obstetric danger sign.
In this study ANC attendance before giving last birth was also positively associated with PNC service utilization. Mothers who have attended at least one ANC visit before giving their last birth were more likely to utilize PNC service than those mothers who have not attended ANC visit at all. This result is consistent with the studies conducted in Lemo Woreda, Hadiya Zone (Belachew et al., 2016), studies done in Rural Ethiopia (Tesfaye et al., 2014), Gondar Zuria District,Ethiopia (Tesfahun et al., 2014) Northwest Ethiopia (Gebeyehu et al., 2013) Abuna Gindeberet District, West Shewa, Oromiya Region (Darega et al., 2016) and Kenya (Nzioki et al., 2015b). However, this result has disparity with the study conducted in Hossana, Ethiopia (Dutamo et al., 2015) and in Maiduguri, north-eastern Nigeria (Usman et al., 2017) which showed that ANC follow up before giving last birth has no significant association with PNC service utilization. The possible reasons for the positive association between ANC attendance and PNC service utilization might be that mothers and their families receive health education and counselling during ANC visits and thus get good access to learn about the benefits of PNC services follow up in health care facilities.

According to this study the utilization of postnatal care was found significantly higher among women who had intended pregnancy as compared to those women whose pregnancy was unintended. Mothers who intended pregnancy desire more likely utilized postnatal care service than those mothers who didn't intended. This finding is supported by local studies conducted in India (Chandra and Kumar, 2017). The possible justification might be women who were joyful with their pregnancy increase the possibility of seek postnatal care-taking services. This result is not in line with the 
Wordofa et al./ Postnatal care service utilization and associated factors among women in Ethiopia

study conducted in Ethiopia (Gebeyehu et al., 2013, Dutamo et al., 2015).

Place of delivery was statistically significantly associated with PNC service utilization. Mothers who gave birth in health institutions were more likely to utilize PNC service than those mothers who were gave birth at home. This finding is also consistent with the study conducted in Lemo woreda, Hadiya zone, south Ethiopia (Belachew et al., 2016), DebreMarkos town, North western Ethiopia (Limenih et al., 2016), Jabitena district Amhara region, Ethiopia (Workineh and Hailu, 2014) and Nepal (Paudel et al., 2013). The possible explanation for this strong positive association of PNC services utilization with place of delivery could be that women who gave birth in health institution have greater opportunity for health education related to PNC services at the time of delivery and thus get access to learning about the types, benefits, and availabilities of PNC services during their stay in the health institutions.

Generally, this study found that more than half of respondents in Goba woreda were not utilized postnatal care service. Even though the first 48 hours a large proportion of maternal and neonatal death occurring and critical time for monitoring complication arising from delivery, this study found that postnatal care service utilization with in this period very low. The reason most of mothers were attended postnatal care service for recent delivery stated that for immunization and family planning and the major reasons for not attended postnatal care service were stated that because of being healthy of both mother and child, didn't think it was necessary and being busy. Maternal educational status, maternal knowledge on postnatal danger sign and symptom, pregnancy plan, ANC attendance and place of delivery were found to be independent predictors for PNC service utilization.

\section{AUTHOR CONTRIBUTION}

All authors had equal contribution on this manuscript.

\section{CONFLICT OF INTEREST}

The authors states that there was no conflict of interest.

\section{FUNDING AND SPONSORSHIP}

Madda Walabu University has supported this study during the design of the study, collection, and analysis, interpretation of data and in writing the manuscript.

\section{ACKNOWLEDGEMENT}

Authors were grateful to Madda Walabu University for supporting this study. We were also very grateful to mothers' and data collectors for their collaboration to undertake this study.

\section{REFERENCE}

Ambel A, Andrews C, Bakilana A, Foster E, Khan Q, Wang H (2015). Maternal and child health inequalities in Ethiopia. Policy Research Working Paper. Retrieved From: http://hdl.handle.net/10986/23805.

Belachew T, Taye A, Belachew $\mathrm{T}$ (2016). Postnatal care service utilization and associated factors among mothers in Lemo Woreda, Ethiopia. Journal of Womens Health Care. 18: 508. http://dx.doi.org/10.4172/2167-0420.1000318.

Belemsaga D, Yugbare, Kouanda S, Goujon A, Kiendrebeogo JA, Duysburgh E, Degomme O, Temmerman M (2015). A review of factors associated with the utilization of healthcare services and strategies for improving postpartum care in Africa afrika focus. 28(2): 83- 
Wordofa et al./ Postnatal care service utilization and associated factors among women in Ethiopia

105. http://ecommons.aku.edu/eastafrica_fhs_mc_obstet_gynaecol/43.

Berhanu S, Asefa Y, Giru B, Wordofa (2016). Prevalence of postnatal care utilization and associated factors among women who gave birth and attending immunization clinic in selected government health centers in Addis Ababa. Med Nursing. 26: 94108. https://www.iiste.org/Journals/index.php/JHMN/article/view/3086 4/o.

Chandra H, Tiwar, Kumar S, Gupta (2017). A study on postnatal care and its correlates among recently delivered women visiting to $\mathrm{BRD}$ medical college Gorakhpur. Int J Community Med Public Health. 4(5): 1548-1551. http://dx.doi.org/10.18203/23946040.ijcmph20171761.

Darega I, Dida N, Tafese F, Ololo S (2016). Institutional delivery and postnatal care services utilizations in Abuna Gindeberet District, West Shewa, Oromiya Region, Central Ethiopia. BMC Pregnancy and Childbirth. A Community-based cross sectional study. https://doi.org/10.1186/s12884-0160940-x.

Dutamo Z, Assefa N, Egata G (2015). Maternal health care use among married women in Hossaina, Ethiopia. BMC Health Services Research. 15: 365. https://doi.org/10.1186/s12913-0151047-1.

Ethiopia Mini Demographic and Health Survey (2014). Addis Ababa, Ethiopia. Ethiopia Demographic and Health Survey (2016). Addis Ababa, Ethiopia.

FMOH (2008). Postnatal care blended learning module for the health extension programme.

Gebeyehu A, Worku A, Yalew, Fantahun MA (2013). Factors affecting of skilled maternalcare in Northwest Ethiopia: a multilevel analysis. BMC Int Health Hum Rights. 13: 20. https://doi.org/10.1186/1472-698x-13-20.

Khanal V, Adhikari M, Aarkee R, Gavidia T (2014). Factors associated with the utilisation of postnatal care services among the mothers of Nepal: analysis of Nepal Demographic and Health Survey (2011). BMC Women's Health. 14:19. https://doi.org/10.1186/14726874-14-19.

Langlois EV, Miszkurka M, Munzunegui MV, Ghafar A, Ziegler D, Karp I (2015). Inequities in postnatal care in low- and middle-income countries. Bull World Health Organization, 259-270. https://doi.org/10.2471/blt.14.140996.

Limenih M, Andualem, Endale Z, Mulaw, Dachew B, Assefa (2016). Postnatal care service utilization and associated factors among women who gave birth in the last 12 months prior to the study in Debre Markos Town, Northwestern Ethiopia. Int J Reprod Med. https://doi.org/10.1155/2016/709535 2.

Matthews M, Severin VX, Jelka Z (2008). Technical consultation on postpartum and postnatal care. World Health Organization, 20 Avenue Appia, 1211 Geneva 27, Switzerland.

Wangari MR (2011). Factors affecting utilization of postnatal care services at central provincial general hospital, Nyeri, Kenya. Thesis. Faculty of Education: University of Nairobi Research Archive. http://erepository.uonbi.ac.$\mathrm{ke} / \mathrm{handle} / \mathbf{1 1 2 9 5 / 4 6 8 3 .}$

Nzioki JM, Onyango RO, Ombaka JH (2015). Socio-demographic factors influencing maternal and child health service utilization in Mwingi: A rural Semi-Arid District in Kenya. Am J 
Wordofa et al./ Postnatal care service utilization and associated factors among women in Ethiopia

Public Health Res. 3(1): 21-30. http://pubs.sciepub.com/ajphr/3/1/4.

Paudel M, Khanal V, Acharya B, Adhikari M (2013). Determinants of postnatal service utilization in a Western District of Nepal: Community based cross sectional study. J Women's Health Care. http://dx.doi.org/10.4172/21670420.1000126.

Save the children (2013). state of the world's mothers 2013. Bill \& Melinda Gates Foundation.

Somefun OD, Ibisomi L (2014). Determinants of postnatal care non-utilization among women in Nigeria. BMC Res Notes. 9: 21. https://doi.org/10.1186/s13104-015-1823-3.

Tafesse M (2015). Assessment of postnatal care utilization and associated factors in Asella town, Regional State of Oromia, Ethiopia.

Tesfahun F, Worku W, Mazengiya F, Kifle $M$ (2014). Knowledge, perception and utilization of postnatal care of mothers in Gondar Zuria District, Ethiopia: A cross-sectional study. Matern Child Health J. 18: 2341-2351. DOI 10.1007/s10995-014-1474-3.

Tesfaye S, Berry D, Gebremariyam A, Hailemichael A, Stover K, Tessema H, Aleminesh L, Lynn M (2014). Improving coverage of postnatal care in rural Ethiopia using a communitybased, collaborative quality improvement approach. J Midwifery Women's Health. 59(1): S55-64. https://reference.medscape.com/viewpublication /870.
Usman I, Dlakwa H, Dataro, Bukar M, Abdu B, Muhamad, Kuwayaura A, Salhiu (2015). Factors responsible for under-utilization of postnatal care services in Maiduguri, North-Eastern Nigeria. 18(3): 109-115. Sahel Med J. DOI: $10.4103 / 1118-8561.169282$.

WHO (2013). Postnatal Care for Mothers and Newborns Highlights from the World Health Organization 2013 Guidelines.

WHO (2014). WHO recommendations on Postnatal care of the mother and newborn. World Health Organization. Geneva.

WHO, UNFPA, World Bank Group and the United Nations Population Division. (2015). Trends in maternal mortality: 1990 to 2015. World Health Organization Geneva, Switzerland.

Workineh YM, Hailu DA (2014). Factors affecting utilization of postnatal care service in Jabitena district, Amhara region, Ethiopia. Science Journal of Public Health 2(3): 169-176. https://dx.doi.org/10.11648/j.sjph.20140203. 15.

Yunus A, Iqbal S, Munawar R, Zakar R, Mushtaq SK, Sadaf F, Usman A (2013). Determinants of Postnatal Care Services Utilization in PakistanInsights from Pakistan Demographic and Health Survey. Middle-East J Sci Res. 18(10): 1440-1447. http://dx.doi.org/10.5829/idosi.mejsr.2013.18.10.12418 . 